\title{
AVALIAÇÃO DA ESPIRITUALIDADE / RELIGIOSIDADE DE PACIENTES EM CUIDADOS PALIATIVOS ${ }^{1}$
}

\author{
Spiritual assessment of patients in palliative care
}

\author{
Mary Rute Gomes Esperandio² \\ Tiago Silva Rosa ${ }^{3}$
}

\section{Resumo:}

De acordo com a Organização Mundial da Saúde, a provisão do cuidado espiritual é parte intrínseca das boas práticas em cuidados paliativos. $O$ objetivo deste estudo foi compreender de que modo a espiritualidade/religiosidade ( $E / R$ ) se relaciona com a saúde/doença no contexto dos cuidados paliativos. Foi utilizada metodologia mista, com aplicação de instrumentos de medida (Escala de Coping Espiritual Religioso e da Escala da Centralidade da Religiosidade) e entrevista fenomenológica. Participaram deste estudo 13 pacientes. A média de centralidade da religiosidade foi de 4.3 e equivale a categoria "altamente religioso/a". Estratégias de Coping Espiritual Religioso Positivo foram altamente utilizadas (média $=4.23$; $D P=1.40)$. A análise das narrativas sugere que a espiritualidade é utilizada como fonte de sentido, conexão com o Sagrado e recurso de enfrentamento do sofrimento. Tais resultados comprovam a relevância da integração da $E / R$ nas práticas de cuidado e indicam a necessidade de uma adequada abordagem curricular dessa temática em cursos de Teologia e da área da Saúde. Futuros estudos devem investigar a efetividade dessa integração na prática dos cuidados em saúde.

Palavras-chaves: Cuidado Espiritual. Cuidados Paliativos. Espiritualidade e Saúde.

\section{Abstract:}

According to the World Health Organization, the provision of spiritual care is an intrinsic part of good practices in palliative care. The aim of this study was to understand how spirituality / religiosity is related to health / illness in the context of palliative care. A mixed methodology was used, with application of measuring instruments (Brief Scale for Spiritual/Religious Coping and Centrality of Religiosity Scale) and phenomenological interview. Thirteen patients participated in this study. The average centrality of religiosity was 4.3 and is equivalent to the "highly religious" category. Positive Spiritual/Religious Coping strategies were highly used (mean $=4.23 ; S D=1.40)$. In narrative analysis, spiritual / religious practices such as prayer, literature and music are used as a form of connection with the Sacred. These results show that

1 Submetido em: 18.02.2020. Aceito em: 08.08.2020.

2 Graduação em Pedagogia pela UNIJUÍ, RS, e em Psicologia pela UNISINOS, RS. Especialização em Terapias Cognitivas e Cuidados Paliativos. Mestrado e Doutorado em Teologia pelas Faculdades EST, São Leopoldo, RS. Psicóloga e Professora na Pontifícia Universidade Católica do Paraná - PUC-PR. Contato: mary.esperandio@pucpr.br.

3 Graduação em Teologia pela Pontifícia Universidade Católica do Paraná, PUC/PR. Mestrando em Teologia na Pontifícia Universidade Católica do Paraná, PUC/PR. Contato: tiago.rosa@pucpr.edu.br.

Protestantismo em Revista | São Leopoldo | v. 46, n. 01 | p. 168-182| Jan./jun. 2020

Disponível em: <http://periodicos.est.edu.br/index.php/nepp> 
spirituality is an important resource to be integrated into care practices. In this sense, the Academy should provide training for health professionals as well as theologians to effectively integrate this dimension into the course of treatment. Future studies should investigate the effectiveness of this integration in health care practice.

Keywords: Spiritual Care. Palliative Care. Spirituality and Health.

\title{
Introdução
}

Vivemos em um século em que o processo de morrer é um processo medicalizado, solitário, silencioso e prolongado. Neste cenário, os Cuidados Paliativos (CP) surgem como um cuidado de conforto que visa a qualidade de vida da unidade de cuidado (pacientes e familiares), através da prevenção e alívio do sofrimento (seja ele físico, psicológico, social ou espiritual). Pactuada durante a 8a Reunião da Comissão Intergestores Tripartite (CIT), a Resolução no 41, apresenta diretrizes voltadas a promoção dos cuidados paliativos no âmbito Sistema Único de Saúde (SUS). Este documento define cuidados paliativos, baseado na definição da Organização Mundial da Saúde (OMS), como:

\begin{abstract}
Assistência promovida por uma equipe multidisciplinar, que objetiva a melhoria da qualidade de vida do paciente e seus familiares, diante de uma doença que ameace a vida, por meio da prevenção e alívio do sofrimento, da identificação precoce, avaliação impecável e tratamento de dor e demais sintomas físicos, sociais, psicológicos e espirituais. ${ }^{4}$
\end{abstract}

Cabe salientar que os CP não são cuidados baseados em protocolos, e sim, em princípios. Um destes princípios é a integração de aspectos espirituais no cuidado ao paciente e seus familiares. Em busca de sentido para experiências de sofrimento muitas pessoas se voltam para a dimensão da E/R. Isso decorre da característica que a E/R tem de ajudar as pessoas a lidarem com os sentimentos decorrentes de situações conflituosas, como uma situação de doença, por exemplo ${ }^{5}$. O uso destes elementos espirituais/religiosos para enfrentar uma situação de estresse e sofrimento, é o que o psicólogo da religião Kenneth Pargament ${ }^{6}$ define como Coping Espiritual/Religioso (CER).

Esta integração da espiritualidade nas práticas de saúde tem sido objeto de estudo de muitos/as pesquisadores/as. ${ }^{7,8}$ Tais pesquisas têm demonstrado a importância da

4 BRASIL. Resolução no 41, de 31 de outubro de 2018. Diário Oficial da União, Brasilia, 2018. Disponível em: <http://www.in.gov.br/web/guest/materia/-/asset_publisher/Kujrw0TZC2Mb/content/id/51520746/do12018-11-23-resolucao-n-41-de-31-de-outubro-de-2018-51520710>. Acesso em: 27 out. 2019.

5 ESPERANDIO, M. R. G. Espiritualidade em cuidados paliativos: contribuições do coping religioso/espiritual. In: CORRADI-PERINI, C.; ESPERANDIO, M. R. G.; SOUZA, W. BIOHCS: Bioética e Cuidados Paliativos. 1. Ed. Curitiba: Editora Prismas, 2016. p. 241-262.

6 PARGAMENT, K. I. Psychology of religion and coping. Theory, Research, Practice. New York: Guilford Press, 1997.

7 KOENIG, H. G. Medicina, religião e saúde: o encontro da ciência e da espiritualidade. Porto Alegre: L\&PM, 2012.

8 MOREIRA-ALMEIDA, A. Espiritualidade e saúde: passado e futuro de uma relação controversa e desafiadora. Rev. psiquiatr. clín., São Paulo, v. 34, supl. 1, p. 3-4, 2007. Disponível em: 
integração da espiritualidade no cuidado ao paciente e os inúmeros benefícios decorrentes de tal associação. Embora este tema esteja em voga, não há um consenso com relação a definição dos termos espiritualidade, religião e religiosidade, portanto, apresentamos as definições que estão sendo aqui empregadas. Espiritualidade é por nós compreendida como:

Aspecto dinâmico e intrínseco da humanidade através do qual as pessoas buscam sentido último, propósito, e transcendência, e experienciam a relação consigo mesmas, com a família, com outros, com a comunidade, a sociedade, a natureza e o significante ou sagrado. A espiritualidade é manifesta através de crenças, valores, tradições e práticas. ${ }^{9}$

Já Religião é aqui entendida como um conjunto de crenças, práticas e rituais relacionados à uma transcendência em seus mais variados e distintos nomes ${ }^{10}$. Derivado da religião, o termo religiosidade, refere-se ao envolvimento da pessoa em atividades religiosas específicas, tais como orações e frequência a cultos, missas, reuniões, dentre outras ${ }^{11}$. Tendo em vista estas definições, utilizaremos aqui o binômio espiritualidade/religiosidade (E/R) pelo fato de entendermos que este consiste na busca de sentido e propósito na vida, podendo esta ser dentro ou fora dos limites de uma religião instituída ${ }^{12}$.

Considerando que diante de enfermidades graves, sobretudo no contexto dos $\mathrm{CP}$, as pessoas se voltam para a dimensão espiritual na busca de sentido para a experiência de sofrimento, o presente estudo teve como objetivo investigar o modo como a $E / R$ funciona neste cenário. Há poucos estudos no Brasil sobre o tema, haja vista que o estabelecimento de serviços de CP no Brasil ainda está em seus inícios. Assim, na seção seguinte apresentaremos um panorama dos estudos brasileiros sobre espiritualidade/religiosidade no contexto dos CP e em seguida serão apresentados os resultados de um estudo empírico junto a pacientes em $\mathrm{CP}$.

\section{As pesquisas sobre espiritualidade/religiosidade junto a pacientes em cuidados paliativos no brasil - panorama atual}

Com objetivo de identificar os artigos acerca deste tema, produzidos no Brasil, foi empreendida uma busca eletrônica no portal de periódicos da CAPES. Utilizando os termos "espiritualidade" AND "cuidados paliativos" AND "pacientes", uma busca inicial resultou na captura de 56 publicações. Os filtros "apenas periódicos revisados por pares" e "artigos em português" foram utilizados para refinar as publicações, resultando em 37 estudos. Após uma

$<$ http://www.scielo.br/scielo.php?script=sci_arttext\&pid=S0101-60832007000700001\&lng=en\&nrm=iso>. Acesso em: 02 dez. 2017.

9 PUCHALSKI, C.; VITILLO, R.; HULL, S. K.; RELLER, N. Improving the spiritual dimension of whole person care: Reaching national and international consensus. J Palliat Med. 2014. p. 646. Disponivel em: $<$ http://citeseerx.ist.psu.edu/viewdoc/download?doi=10.1.1.866.2561\&rep=rep1\&type=pdf>. Acesso em: 28 Nov. 2018.

10 KOENIG, H. G.; KING, D. E.; CARSON, V. B. Handbook of religion and health (2 Ed.). New York, NY: Oxford University Press, 2012. p. 45.

11 ESPERANDIO, M.R.G. Teologia e a pesquisa sobre espiritualidade e saúde: um estudo piloto entre profissionais da saúde e pastoralistas. Horizonte, Belo Horizonte, v. 12, n. 35, p. 808, jul./set. 2014.

12 ESPERANDIO, M. R. G.; MICHEL, R. B.; TREBIEN, H. A. C.; MENEGATTI, C. L. Coping Religioso/Espiritual na Antessala de UTI: Reflexões sobre a Integração da Espiritualidade nos Cuidados em Saúde. Interações - Cultura e Comunidade (Online). Belo Horizonte, v. 12, p. 306, 2017.

Protestantismo em Revista | São Leopoldo | v. 46, n. 01 | p. 168-182| Jan./jun. 2020

Disponível em: <http://periodicos.est.edu.br/index.php/nepp> 
leitura minuciosa desse material, foram descartados os estudos de abordagem teórica ou que não tinham como foco principal a pesquisa sobre espiritualidade. Foram selecionados para análise apenas artigos científicos que apresentaram resultados de pesquisas empíricas realizadas no Brasil junto a pacientes em CP, publicados em português. Desse modo, três artigos compuseram a seleção para a presente análise. (Quadro 1).

Quadro 1 - Distribuição dos estudos

\begin{tabular}{|c|c|c|c|c|}
\hline Autoria/Título & $\begin{array}{l}\text { Ano/Local do } \\
\text { Estudo }\end{array}$ & Objetivo & Método/Resultados & $\begin{array}{l}\text { Principais } \\
\text { Achados }\end{array}$ \\
\hline $\begin{array}{l}\text { ELIAS, A. C. A.; GIGLIO, J. S.; } \\
\text { PIMENTA, C. A. M./ Análise } \\
\text { da natureza da dor espiritual } \\
\text { apresentada por pacientes } \\
\text { terminais e o processo de sua } \\
\text { re-significação através da } \\
\text { intervenção relaxamento, } \\
\text { imagens mentais e } \\
\text { espiritualidade (RIME). }\end{array}$ & $\begin{array}{l}2008 / \\
\text { Campinas, São } \\
\text { Paulo e } \\
\text { Piracicaba. }\end{array}$ & $\begin{array}{l}\text { Estudar a } \\
\text { natureza da } \\
\text { Dor Espiritual } \\
\text { e sua re- } \\
\text { significação } \\
\text { durante a } \\
\text { aplicação da } \\
\text { Intervenção } \\
\text { RIME. }\end{array}$ & 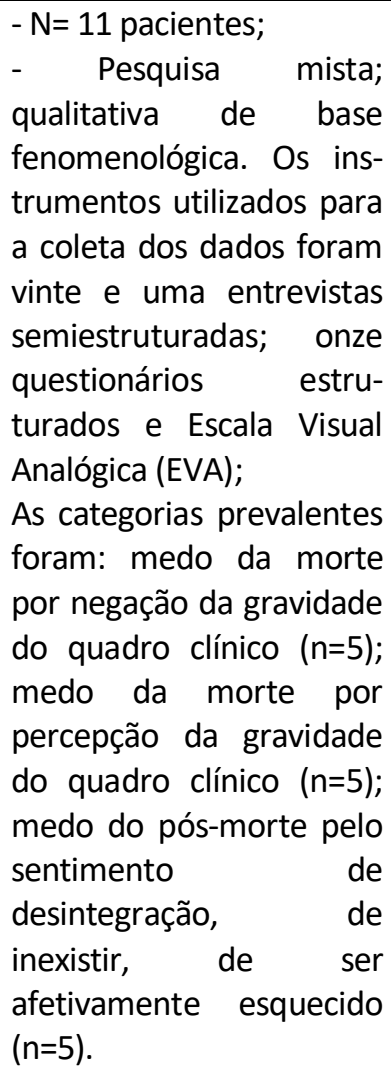 & $\begin{array}{l}\text { A RIME pro- } \\
\text { moveu quali- } \\
\text { dade de vida } \\
\text { no processo de } \\
\text { morrer, assim } \\
\text { como mais } \\
\text { serenidade e } \\
\text { dignidade } \\
\text { perante a } \\
\text { morte. }\end{array}$ \\
\hline $\begin{array}{l}\text { FORNAZARI, S. A.; FERREIRA, } \\
\text { R. E. R./ } \\
\text { Religiosidade/espiritualidade } \\
\text { em pacientes oncológicos: } \\
\text { qualidade de vida e saúde. }\end{array}$ & $\begin{array}{l}\text { 2010/ } \\
\text { São Paulo. }\end{array}$ & $\begin{array}{l}\text { Investigar o } \\
\text { enfren- } \\
\text { tamento } \\
\text { religioso. }\end{array}$ & $\begin{array}{l}\text { - N= } 10 \text { pacientes; } \\
\text { - Para a coleta de dados, } \\
\text { foi utilizado um roteiro de } \\
\text { entrevista. } \\
\text { O conteúdo desses relatos } \\
\text { aponta para o uso de } \\
\text { estratégias, onde foi } \\
\text { possível levantar cinco } \\
\text { categorias: Suporte } \\
\text { Emocional, Cura (transfor- } \\
\text { mação de vida), Busca de } \\
\text { Significado, Contribuições } \\
\text { no Tratamento e Controle. }\end{array}$ & 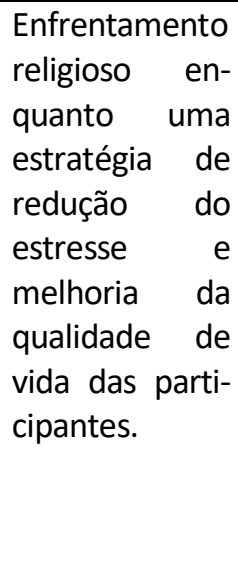 \\
\hline
\end{tabular}




\begin{tabular}{|c|c|c|c|c|}
\hline 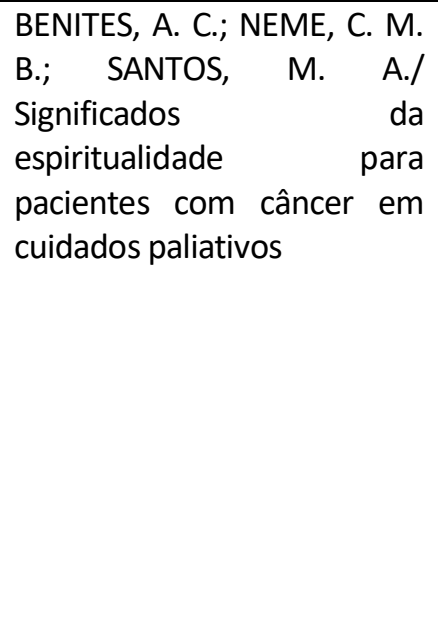 & $\begin{array}{l}\text { 2017/ } \\
\text { Barretos }\end{array}$ & $\begin{array}{l}\text { Compreender } \\
\text { as vivências e } \\
\text { o significado } \\
\text { da } \\
\text { espiritualidade } \\
\text { ante a dor do } \\
\text { adoecimento } \\
\text { e a } \\
\text { possibilidade } \\
\text { de morte. }\end{array}$ & $\begin{array}{l}\text { - } \mathrm{N}=10 \text { pacientes; } \\
\text { Foi utilizado o método } \\
\text { fenomenológico para } \\
\text { coleta e análise dos } \\
\text { relatos, que foram obtidos } \\
\text { a partir de entrevistas } \\
\text { individuais. } \\
\text { Evidenciou-se } \\
\text { importância da dimensão } \\
\text { espiritual na vivência do } \\
\text { processo de morrer, } \\
\text { possibilitando a busca de } \\
\text { sentidos para a vida e para } \\
\text { a morte. }\end{array}$ & $\begin{array}{l}\text { Estar ante a } \\
\text { morte leva à } \\
\text { veneração da } \\
\text { vida }\end{array}$ \\
\hline
\end{tabular}

Fonte: Dados da Pesquisa

Percebe-se a predominância de estudos de base qualitativa. Tais pesquisas demonstram que a espiritualidade/religiosidade é uma dimensão que está sendo integrada pelos/as pacientes como um recurso para o enfrentamento da doença e de ressignificação do processo de morte. Os resultados desta integração mostram-se muito positivos tendo impacto até mesmo na qualidade de vida dos/as pacientes e na melhor aceitação do processo de morte. Embora estes estudos abordem apenas os resultados positivos, crenças espirituais/religiosas podem ser empregadas de maneira negativa, funcionando como um lócus de conflito, o que pode afetar na tomada de decisões acerca do tratamento levando o indivíduo a entrar em conflito com os tratamentos médicos e em alguns casos a rejeitá-los ${ }^{13}$. Daí a necessidade da aplicação de instrumentos que avaliem a presença de conflitos espirituais/religiosos entre pacientes em cuidados paliativos. Um instrumento que se mostra útil para esta avaliação é a Escala de Conflitos Espirituais, ainda em processo de validação no Brasil. Os três estudos somam 31 pacientes. Todos foram realizados com pacientes diagnosticados/as com câncer. As pesquisas se concentram na região sudeste, região que congrega $50 \%$ dos serviços de cuidados paliativos do país ${ }^{14}$. Dos estudos selecionados, um foi realizado desde uma abordagem interdisciplinar por profissionais da medicina, psicologia e enfermagem, e os outros dois por profissionais da psicologia. O estado da arte evidencia que embora este tema esteja tão em voga, há a necessidade do desenvolvimento de pesquisas empíricas, que associem a espiritualidade aos cuidados paliativos, sobretudo levando-se em conta as narrativas e vivências dos/as pacientes.

\section{Metodologia}

Considerando o objetivo desse estudo, o método utilizado para levantamento de dados foi de abordagem mista, de corte transversal (a coleta de dados ocorre em um só momento), com aplicação de um questionário para a coleta dos dados sociodemográficos,

13 KOENIG, 2012.

14 ACADEMIA NACIONAL DE CUIDAdOS PALIATIVOS. Panorama dos Cuidados Paliativos no Brasil. São Paulo, 2018.

Protestantismo em Revista | São Leopoldo | v. 46, n. 01 | p. 168-182| Jan./jun. 2020

Disponível em: <http://periodicos.est.edu.br/index.php/nepp> 
instrumentos de avaliação da espiritualidade: Escala de Centralidade da Religiosidade $(E C R)^{15}$ e Escala de Coping Espiritual/Religioso $(E C E R)^{16}$, e realização de entrevista semi-estruturada.

A Escala de Centralidade da Religiosidade, é composta por dez itens e objetiva avaliar cinco dimensões que podem ser vistas como representativas do conjunto da vida religiosa. Tais dimensões são: intelectual (indicada pela frequência com que a pessoa pensa sobre questões religiosas), ideológica (indicada pela plausabilidade da existência da realidade transcendente), prática pública (indicada pela frequência com que o indivíduo participa em atividades religiosas), prática privada (indicada pela intensidade com a qual o indivíduo realiza práticas como oração e meditação) e a dimensão da experiência religiosa (indicada pela intensidade com que o indivíduo se confronta com questões acerca da realidade última).

A Escala de Coping Espiritual/Religioso (CER - 14), é um instrumento composto por 14 itens, sendo que sete indicam o CER positivo e os outros sete referem-se a estratégias de CER negativo. Das estratégias de coping:

[...] O CER Positivo refere-se ao senso de espiritualidade, a um relacionamento seguro com Deus, à crença de que existe um sentido na vida a ser encontrado e ao senso de conexão com outros. O CER Negativo expressa-se por meio de um relacionamento menos seguro com Deus; uma visão de mundo frágil e ameaçadora, e conflitos espirituais na busca por propósito e sentido ${ }^{17}$.

A entrevista teve como referencial metodológico a fenomenologia. O Roteiro semiestruturado foi composto por cinco perguntas: 1. Nesta situação de doença que você está vivendo nesse momento, imagino que há várias mudanças em relação aquilo que você considera necessário para você ficar bem. Caso se sinta confortável, poderia nos falar um pouco sobre o que você considera que "precisa" ou que sente como "necessário"? Quais as suas principais necessidades? (Qualquer uma: seja física, de amor, segurança, de estima, de realização pessoal); 2. O que ajuda você a enfrentar tempos difíceis (como o processo de tratamento do seu familiar, por exemplo)?; 3. Em quem você se apega (ou para quem você se volta) nessa situação que você está enfrentando? (Grau de parentesco). Essa pessoa supre o que você precisa?; 4 . Que sentido tem essa experiência para você?; 5 . Com quem você gostaria de estar ou com quem você gostaria de estar neste momento?

A investigação de caráter qualitativo procedeu da seguinte maneira: 1) realização da entrevista gravada em áudio; 2) transcrição destas entrevistas, realizada por meio da plataforma online oTranscribe; 3) categorização e análise dos dados. Como procedimentos de análise da entrevista fenomenológica, Giorgi e Sousa (2010) propõem os seguintes passos: 1) estabelecer o sentido geral; 2) determinação das partes - divisão das unidades de significado; 3) transformação das unidades de significado em expressões de caráter psicológico; 4) determinação da estrutura geral de significados psicológicos. O critério utilizado para escolha das constituintes essenciais foi a seleção de trechos considerativos para o problema em

15 ESPERANDIO, M. R. G.; AUGUST, H. ; VIACAVA, J. J. C. ; HUBER, S. ; FERNANDES, M. L. Brazilian Validation of Centrality of Religiosity Scale (CRS-10BR and CRS-5BR). Religions, v. 10, p. 508, 2019.

16 ESPERANDIO, M. R. G.; ESCUDERO, F. T.; FERNANDES, M. L.; PARGAMENT, K. Brazilian Validation of the Brief Scale for Spiritual/Religious Coping-SRCOPE-14. Religions, v. 9, p. 31, 2018.

17 PARGAMENT, K. I.; SMITH, B. W.; KOENIG, H. G.; PEREZ, L. Patterns of Positive and Negative Religious Coping with Major Life Stressors. Journal for the Scientific Study of Religion, 37 (4), 1998. p. 712, tradução nossa.

Protestantismo em Revista | São Leopoldo | v. 46, n. 01 | p. 168-182| Jan./jun. 2020

Disponível em: <http://periodicos.est.edu.br/index.php/nepp> 
questão, ou seja, trechos que abordem as necessidades e os recursos psico-espirituais dos/as pacientes.

Este estudo teve a Aprovação do Comitê de Ética em Pesquisa (Parecer 1.954.260). Foram critérios de inclusão na pesquisa, a participação voluntária, ser maior de 18 anos, ser capaz de compreender as questões. Foram excluídos do estudo aqueles/as pacientes que estavam em condições médicas mais fragilizadas. Participaram do estudo 13 idosos/as hospitalizados/as e os dados foram coletados em um hospital na cidade de Curitiba, Estado do Paraná.

As entrevistas foram realizadas com pacientes que, de acordo com a literatura, teriam maiores benefícios decorrentes de uma boa prática de $\mathrm{CP}$, são estes/as: pacientes idosos/as maiores de 65 anos, diagnosticados/as com doenças crônicas; pacientes oncológicos com mal prognóstico; além de pacientes que estivessem propriamente em cuidados paliativos, com o requisito de que não estivessem muito debilitados/as. A seleção dos participantes contou com a ajuda da equipe de enfermagem do local onde a pesquisa foi realizada.

\section{Resultados}

\section{Perfil da Amostra}

Participaram deste estudo 13 colaboradores/as. A média de idade dos/as colaboradores/as foi de 68.23 anos, variando de 49 a 78 anos. $53.85 \%$ são do sexo feminino e $46.15 \%$ são do sexo masculino. Em relação à escolaridade: 7 , têm o ensino fundamental incompleto; 1 , tem o ensino fundamental completo; 1 , tem o ensino médio incompleto; 1 , tem o ensino médio completo; 1 , tem o ensino superior completo e 2 , são pós-graduados/as. Quanto ao estado civil, $53.85 \%$ são casados/as, $7.7 \%$ viúvos/as, $23.07 \%$ separados/as ou divorciados/as e $15.38 \%$ solteiros/as. Quanto a ocupação profissional, $61.54 \%$ estão aposentados/as, $7.7 \%$ afastados/as com benefício do INSS, $7.7 \%$ desempregados/as e $23.07 \%$ estão empregados/as.

No que concerne a dimensão espiritual/religiosa, $92.30 \%$ se consideram religiosos/as e espiritualizados/as e $7.70 \%$ se consideram espiritualizados/as, mas não religiosos/as. Todos/as os/as participantes afirmaram acreditar em Deus. Destes/as: $69.23 \%$ afirmaram ser católicos/as; 3 declararam dupla pertença, dos quais: 23,07\% relataram dupla pertença (Cristã e Rosa-cruz; Umbandista e Católico/a; e Espírita e Católico/a); e, por fim, 1 participante disse acreditar em Deus, mas não ter uma religião.

Todos/as os/as entrevistados/as relataram receber apoio durante o tratamento. A grande maioria relatou receber apoio de familiares, como filhos/as, esposo/a, e também de vizinhos/as e amigos/as. A maior parte dos/as participantes afirma ter interesse em conversar com a equipe de saúde acerca de questões relativas à espiritualidade/religiosidade (76,92\%). Os que reportaram dúvida sobre se gostariam de trazer ou não essas questões para o tratamento, $7.7 \%$, ou que disseram que não gostariam, $15.38 \%$, justificaram sua resposta alegando que os/as profissionais de saúde não têm tempo para discutir estas questões, eles/as estão ali para conversar somente acerca da doença. Apenas $30.77 \%$ dos/as participantes relataram terem sido questionados/as pela equipe de saúde acerca de assuntos espirituais/religiosos, o que confirma o receio destes em conversar acerca destas questões. $A$

Protestantismo em Revista | São Leopoldo | v. 46, n. 01 | p. 168-182| Jan./jun. 2020

Disponível em: <http://periodicos.est.edu.br/index.php/nepp> 
média do tempo de tratamento foi de 5.28 anos, variando de 1 mês até 16 anos de tratamento. Os diagnósticos mais prevalentes foram: insuficiência cardíaca e câncer (mama, pulmão, cabeça, cólon, ovário, rim, esôfago e estômago).

\section{Centralidade da Religiosidade e Coping Espiritual/Religioso}

As escalas utilizadas na avaliação da espiritualidade/religiosidade dos/as pacientes em CP demonstram que a religiosidade é central na vida dos participantes do estudo, com média de 4.3 ( $D P=1.23$ ), e que o uso do Coping Espiritual/Religioso Positivo é alto, com média de 4.23 ( $D P=1.40)$. Através de análise estatística descritiva, observou-se que a dimensão central da religiosidade mais prevalente foi a do tipo "Prática privada" ( $M=4,88 D P=0,44)$, dimensão caracterizada pela prática de oração e meditação. A dimensão central de menor prevalência foi do tipo "Dimensão da experiência religiosa" ( $M=3,72 D P=1,51)$, referente a intensidade com que a pessoa se confronta com questões acerca da realidade última. As 5 dimensões estão listadas no Gráfico 1.

Gráfico 1: Fatores das dimensões centrais de religiosidade de acordo com a média

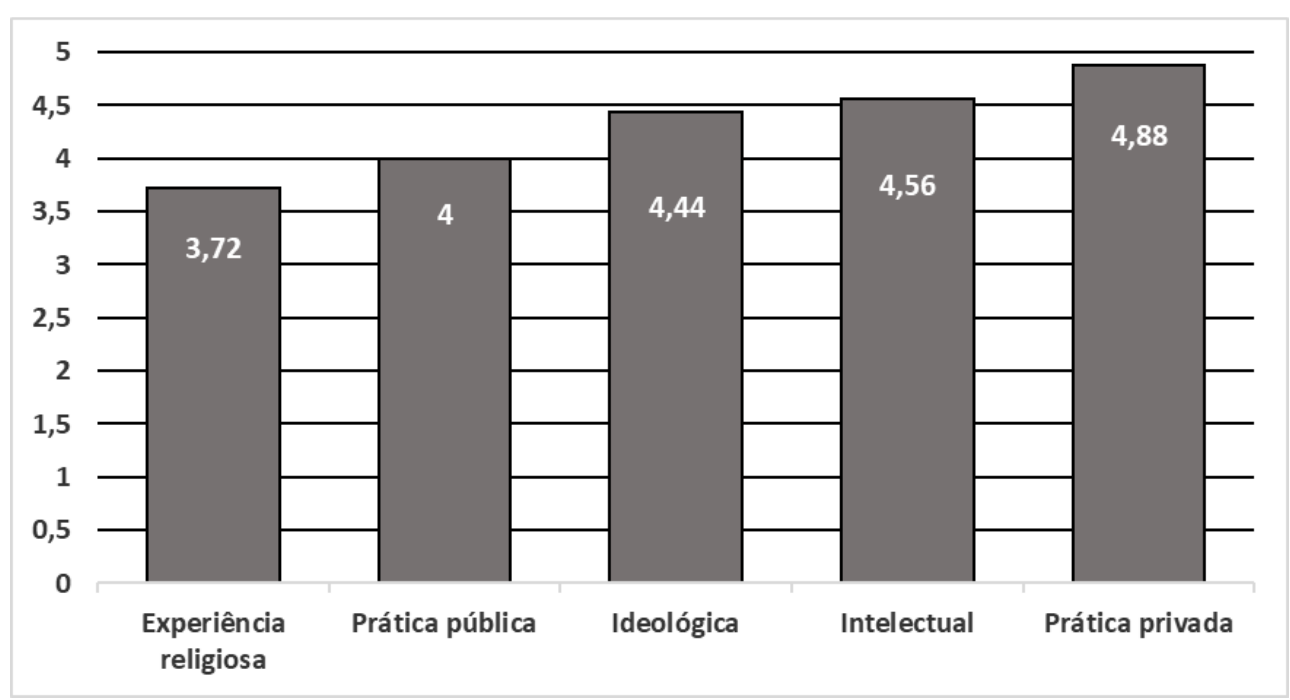

Fonte: dados da pesquisa, 2019.

As afirmações concernentes ao método de CER positivo mais utilizadas, foram: "Tentei ver como Deus poderia me fortalecer nesta situação" ( $M=5 \mathrm{DP}=0)$; "Pedi perdão pelos meus erros (ou pecados)" ( $M=4.61 \mathrm{DP}=0.96)$. Já as afirmações relacionadas ao método de $C E R$ negativo mais utilizadas, foram: "Fiquei imaginando o que eu fiz para Deus me castigar" ( $M=2$ $D P=1.58)$; e "Questionei o amor de Deus por mim" (M=2 DP=1.63). Os dados também apontam que $92.3 \%$ dos/as participantes fazem um uso alto ou altíssimo de CER positivo e $84.61 \%$ não utilizam ou tem uma utilização baixa de CER negativo (como pode ser visto no gráfico 2). 
Gráfico 2: Comparação quanto a frequência dos diferentes padrões de CER em porcentagem

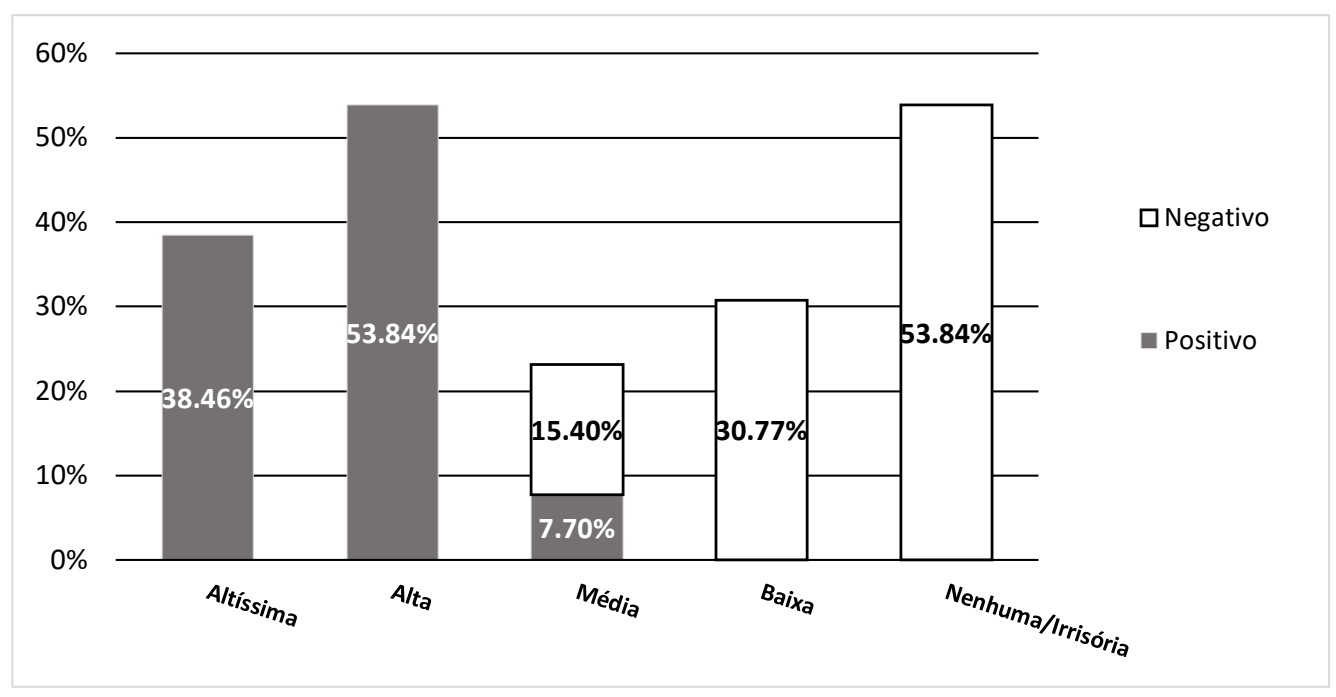

Fonte: dados da pesquisa, 2019.

\section{Entrevista fenomenológica}

A aplicação dos passos propostos por Giorgi e Sousa (2010) na entrevista fenomenológica permitiu categorizar os dados em duas grandes unidades de sentido: os recursos psico-espirituais de enfrentamento do sofrimento e as necessidades percebidas no contexto de tratamento.

\section{Recursos psico-espirituais}

\section{Espiritualidade/religiosidade como fonte de sentido e conexão com o sagrado}

Os/as participantes do estudo reportam o acesso à dimensão espiritual como fonte onde buscam sentido para a experiência de sofrimento, conexão com o sagrado, consigo e com outros, e também como recurso de enfrentamento do sofrimento advindo neste contexto da doença, através da prática de rituais espirituais/religiosos. A dimensão espiritual aparece descrita como "fé" e está presente na experiência cotidiana dos/as pacientes.

\footnotetext{
Se você não tiver aquela fé que sabe que vai levantar do seu leito e vai ir para a sua casa, você nunca é curado. Agora se você tem fé, dizendo: "Eu vou levantar deste leito e vou para a minha casa no dia que Deus quiser", você fica bom. (Participante Feminina, 78 anos).
}

Na dimensão espiritual, os/as pacientes tanto buscam sentido e força como também é ali que encontram sustentação para tomadas de decisão para prosseguir com o tratamento. Em suas narrativas, vemos afirmações como:

“o que me ajuda é Deus. Me agarro com ele e não tenho outra coisa para te dizer. É Deus, Deus e Deus". (Participante Masculino, 66 anos).

Protestantismo em Revista | São Leopoldo | v. 46, n. 01 | p. 168-182| Jan./jun. 2020

Disponível em: <http://periodicos.est.edu.br/index.php/nepp> 
"Eu não aceitava a doença. Aí foi a espiritualidade que me encaminhou, que me disse: 'Não, vai e faça porque você vai viver'”. (Participante Feminina, 71 anos).

Os/as participantes vêem os/as profissionais como sendo capacitados/as por Deus: "os médicos da terra têm aquele poder de tratar das pessoas que estão com problemas, mas também tem o poder da mão de Jesus para poder fazer aquilo". (Participante Feminina, 78 anos)

Espiritualidade/religiosidade como conexão com o sagrado e recurso de coping

A conexão com o sagrado é buscada em práticas tais como a oração, a literatura e as músicas religiosas.

Todo o dia nós fazemos oração aqui no quarto [...] Porque Deus está no meio de nós, ele diz assim: "Onde estiver dois ou três reunidos eu estou no meio", está escrito na Bíblia. (Participante Feminina, 78 anos).

A oração é utilizada tanto como fonte de conexão com o sagrado quanto como estratégia de coping espiritual/religioso, e é a estratégia de coping mais presente nas narrativas:

No dia em que eu não faço oração eu sinto que falta alguma coisa. A oração me dá força, eu acho que é o principal. $O$ ato principal que temos que ter é a oração. (Participante Feminina, 64 anos).

Além da oração, recursos como a literatura e músicas de cunho religioso aparecem como práticas positivas de coping.

"Parece que dá uma reformada escutar um hino muito bonito, uma palavra, capítulo ou versículo. Eu acho que transforma. Ajuda muito em nossa vida espiritual". (Participante Masculino, 66 anos).

Outro recurso espiritual/religioso reportado nas narrativas dos/das participantes refere-se ao suporte da comunidade religiosa:

Na hora em que a gente se sente meio sozinho, a gente vai em uma igreja ou na associação espírita e sente aquela união e aquela força. (Participante Masculino, 67 anos).

\section{As necessidades psico-espirituais}

Muitas dificuldades decorrem de uma situação de doença que ameaça a continuidade da vida. No levantamento das necessidades psico-espirituais emergiram as referidas à conexão consigo mesmos e com o outro-significativo. Estas necessidades apareceram expressas tanto na frustração pela interrupção de um trabalho onde a pessoa se sentia conectada com seu potencial criativo, quanto na vontade de estar em casa com os/as familiares com os/as quais se sentem mais próximos. 
A necessidade de conexão consigo mesmo por meio do trabalho criativo ou de contato íntimo com a natureza aparece na esperança de restabelecimento da saúde para voltar a tais atividades. Assim expressam os/as participantes:

[...] não é nem pelo dinheiro, é mais pelo amor mesmo, por gostar de fazer o que eu sempre fiz. Uma coisa que eu fazia com amor. Sinto falta. (Participante Masculino, 49 anos).

Eu queria só não estar aqui. Só isso. Queria estar em casa. O que me basta é mexer com a minha grama, isso me basta. (Participante Masculino, 72 anos).

A necessidade de conexão com o outro-significativo é expressa tanto pelo desejo de estar com a família, quanto pelo de estar com seu grupo religioso:

Eu quero ir embora, quero que o médico chegue aqui daqui a pouco e me diga para ir terminar o meu tratamento em casa, porque não tem nada o que fazer [...]. Quero ir para casa e ficar com a minha família, com os meus netos e com a minha mulher. (Participante Masculino, 70 anos).

Antes da cirurgia eu ia toda a quarta-feira e na primeira sexta-feira do mês na missa. No centro espírita eu ia toda segunda-feira. Era o meu caminho. [...] Eu espero que as coisas se normalizem para eu voltar minha vida ao normal". (Participante Feminina, 71 anos).

\section{Discussão}

Eric Cassell (1982) observa que para além do sofrimento físico causado pela doença, "o sofrimento é experienciado pelas pessoas, não meramente pelos corpos, e sua fonte está nos desafios que ameaçam a integridade da pessoa como um ser psicológico e social complexo"18. Assim, ao buscar sentido para a experiência de sofrimento, os/as pacientes em $\mathrm{CP}$ encontram na dimensão espiritual, alívio, conforto, propósito, recursos diversos para melhor enfrentarem tal situação de vulnerabilidade.

Os resultados levantados confirmam as observações de Pargament (1997) onde o autor destaca que a espiritualidade provê sentido, significado e identidade. Isto se confirma nas narrativas dos participantes onde estes/as reportam encontrar sentido e significado na experiência, por meio de sua fé. Sua identidade é confirmada também por meio do grupo religioso que assumem e do sofrimento que a hospitalização causa, por limitar o acesso e participação nas práticas religiosas de suas comunidades. O conforto, vivenciado em emoções positivas como paz, gratidão, bom relacionamento com os/as profissionais da saúde, vendoos/as como agentes de Deus para ajudá-los/as nesses momentos, é evidenciado nas narrativas dos/as pacientes.

Além de uma importante fonte na produção de sentido, conexão consigo, com o outro, com a transcendência, a espiritualidade se mostrou como recurso de enfrentamento e como provedora de estratégias para melhor lidar com as sensações de isolamento e tristeza que comumente afetam as pessoas hospitalizadas, com doenças graves. Na amostra participante desse estudo, a espiritualidade também favoreceu o atendimento das necessidades dos/as pacientes.

18 CASSELL, E.J. The Nature of Suffering and the Goals of Medicine. N. Engl. J. Med., v. 306, n.11, p. 639, 1982, tradução nossa.

Protestantismo em Revista | São Leopoldo | v. 46, n. 01 | p. 168-182| Jan./jun. 2020

Disponível em: <http://periodicos.est.edu.br/index.php/nepp> 
Portanto, para que se possa oferecer um cuidado mais humanizado, a equipe de saúde deve estar preparada para lidar com os fatores espirituais/religiosos. Na mesma linha de Cassell, Koenig ${ }^{19}$ defende que "o paciente é uma pessoa única com necessidades físicas, psicológicas, sociais e espirituais que devem ser respeitadas se for para potencializar o tratamento médico e tratar a pessoa inteira".

Os resutados também mostram a importância de se pensar uma teologia além do meio eclesial. Chemin e Souza advertem que

É possível o avanço da ciência teológica para o espaço público, especificamente aquele ligado à prestação de cuidados em saúde, tendo a atuação do teólogo como o profissional responsável pela assistência espiritual em ambientes hospitalares. ${ }^{20}$

O currículo de muitos cursos na área de Teologia não enfatiza a capelania, ou o cuidado espiritual, como uma disciplina fundamental. No entanto, a capelania hospitalar apresenta-se como uma das principais áreas de atuação para estes/as profissionais. Cabe também ressaltar a necessidade da capacitação com conteúdo teológico e clínico de teólogos e teólogas para que possam atuar nesta frente tão importante e ainda muito negligenciada que é a oferta de um cuidado espiritual especializado. Compreendemos que estes/as são profissionais qualificados/as para avaliar e triar a condição de sofrimento espiritual dos/as pacientes, respeitando as crenças sem julgamentos ou condenações. Este preparo é fundamental para que haja um cuidado espiritual efetivo e não a prática de proselitismo religioso que é o que mais presenciamos.

Grande parte dos/as entrevistados/as afirma que gostariam que os/as profissionais de saúde abordassem questões relativas à espiritualidade/religiosidade o que ressalta a necessidade de haver um preparo das equipes para que possam melhor atender estas questões. Isso reforça a importância do/a especialista em assistência espiritual oferecer treinamentos para que membros da equipe multidisciplinar sejam capazes de aplicar a anamnese espiritual aos pacientes, documentar informações mais relevantes no prontuário e dar os encaminhamentos necessários.

\section{Considerações finais}

Os cuidados paliativos no Brasil ainda estão em fase de estabelecimento e com um alcance ainda muito restrito, o que reforça a urgência na promoção de políticas públicas voltadas ao seu estabelecimento. Na prática, cuidados paliativos são erroneamente compreendidos como cuidados de fins de vida, o que impede a prática de um cuidado espiritual e psicológico adequado. Estratégias de CER estão sendo utilizadas com o objetivo de enfrentar o estresse e o sofrimento experienciados durante o tratamento, o que reforça que estas estratégias são relevantes de serem incluídas na terapêutica por toda a equipe de saúde. Não há como ofertar um cuidado integral se estas dimensões não forem incluídas na assistência.

19 KOENIG, 2012, p. 160.

20 CHEMIN, M. R. C.; SOUZA, W. Um diálogo possível entre teologia e sociedade: assistência espiritual nos cuidados em final de vida. Estudos Teológicos, v. 58, p. 159, 2018.

Protestantismo em Revista | São Leopoldo | v. 46, n. 01 | p. 168-182| Jan./jun. 2020

Disponível em: <http://periodicos.est.edu.br/index.php/nepp> 
O uso positivo de métodos de CER certamente traz mais qualidade de vida, conforme já apontado nas páginas anteriores. Além disso, quando o uso é positivo, o/a profissional pode estimular o seu uso e certamente o/a paciente se sentirá mais compreendido/a pelo/a profissional de saúde, fortalecendo o vínculo entre ambos/as. Por outro lado, a utilização de estratégias negativas de $C E R$, pode mostrar aos/às profissionais da saúde a necessidade de uma intervenção adequada, quer ajudando o/a paciente a refletir sobre suas crenças negativas, quer encaminhando-o/a para a pastoral prestar uma assistência devida. Os dados coletados balizam, ainda, proposições de cuidado "baseados-em-evidência, uma vez que foram levantados mediante uma pesquisa científica.

É de fundamental importância a atuação de teólogos e teólogas no contexto da saúde, como cuidadores/as espirituais especializados/as, atuação que requer uma formação adequada para que possam avaliar e triar a condição de sofrimento espiritual dos/as pacientes, com especial respeito a crença/descrença destes/as e também oferecer treinamentos aos/às demais integrantes da equipe de saúde para que estes/as aprendam a abordar melhor estas questões. Cabe, por fim, assinalar que oferecer um cuidado espiritual não tem nada a ver com a crença ou descrença do/a profissional e também não é sugerir nem prescrever religião.

A análise das narrativas nos permite concluir que a dimensão espiritual tem promovido recursos de enfrentamento e a elaboração de sentidos que ressignificam o processo de adoecimento e de morte. A doença é apresentada como um obstáculo a ser vencido, e a fé fornece a possibilidade de vencê-lo. Até mesmo a morte não é vista como uma derrota, mas sim como uma passagem e uma morte digna e sem sofrimento é apresentada em muitas narrativas. Os resultados aqui apresentados não podem ser generalizados uma vez que o número de participantes é muito limitado, portanto, faz-se necessário continuar os estudos que correlacionem espiritualidade e saúde, sobretudo no contexto dos cuidados paliativos, a fim de propor diretrizes que atendam a um cuidado em saúde na perspectiva da pessoa como um todo.

\section{Referências}

ACADEMIA NACIONAL DE CUIDADOS PALIATIVOS. Panorama dos Cuidados Paliativos no Brasil. São Paulo, 2018. Disponível em: https://paliativo.org.br/wpcontent/uploads/2018/10/Panorama-dos-Cuidados-Paliativos-no-Brasil-2018.pdf. Acesso em: 28 out. 2019.

BENITES, A. C.; NEME, C. M. B.; SANTOS, M. A. Significados da espiritualidade para pacientes com câncer em cuidados paliativos. Estud. Psicol. (Campinas), Campinas, v. 34, n. 2, p. 269279, jun. 2017. Disponível em: http://www.scielo.br/scielo.php?script=sci_arttext\&pid=S0103166X2017000200269\&Ing=en\&nrm=iso. Acesso em: 01 out. 2019.

BRASIL. Resolução no 41, de 31 de outubro de 2018. Diário Oficial da União, Brasilia, 2018. Disponível em: http://www.in.gov.br/web/guest/materia/Lasset publisher/Kujrw0TZC2Mb/content/id/51520746/do1-2018-11-23-resolucao-n-41-de31-de-outubro-de-2018-51520710. Acesso em: 27 out. 2019.

Protestantismo em Revista | São Leopoldo | v. 46, n. 01 | p. 168-182| Jan./jun. 2020

Disponível em: <http://periodicos.est.edu.br/index.php/nepp> 
CASSELL, E.J. The Nature of Suffering and the Goals of Medicine. N. Engl. J. Med., v. 306, n.11, p. 639-45, 1982.

CHEMIN, M. R. C.; SOUZA, W. Um diálogo possível entre teologia e sociedade: assistência espiritual nos cuidados em final de vida. Estudos Teológicos, v. 58, p. 148-162, 2018.

ELIAS, A. C. A.; GIGLIO, J. S.; PIMENTA, C. A. M. Análise da natureza da dor espiritual apresentada por pacientes terminais e o processo de sua re-significação através da intervenção relaxamento, imagens mentais e espiritualidade (RIME). Rev. Latino-Am. Enfermagem, Ribeirão Preto, v. 16, n. 6, p. 959-965, dez. 2008. Disponível em: http://www.scielo.br/scielo.php?script=sci_arttext\&pid=S0104-

$11692008000600004 \&$ Ing=en\&nrm=iso. Acesso em: 01 out. 2019.

ESPERANDIO, M.R.G. Teologia e a pesquisa sobre espiritualidade e saúde: um estudo piloto entre profissionais da saúde e pastoralistas. Horizonte, Belo Horizonte, v. 12, n. 35, p. 805832, jul./set. 2014. Disponível em: http://periodicos.pucminas.br/index.php/horizonte/article/view/P.21755841.2014v12n35p805/7119. Acesso em: 15 maio 2019.

ESPERANDIO, M. R. G. Espiritualidade em cuidados paliativos: contribuições do coping religioso/espiritual. In: CORRADI-PERINI, C.; ESPERANDIO, M. R. G.; SOUZA, W. BIOHCS: Bioética e Cuidados Paliativos. 1. Ed. Curitiba: Editora Prismas, 2016. p. 241-262.

ESPERANDIO, M. R. G.; MICHEL, R. B.; TREBIEN, H. A. C.; MENEGATTI, C. L. Coping Religioso/Espiritual na Antessala de UTI: Reflexões sobre a Integração da Espiritualidade nos Cuidados em Saúde. Interações - Cultura e Comunidade (Online). Belo Horizonte, v. 12, p. 303 - 322, $2017 . \quad$ Disponível em: http://periodicos.pucminas.br/index.php/interacoes/article/view/P.19832478.2017v12n22p303/12912. Acesso em: 15 maio 2019.

ESPERANDIO, M. R. G.; AUGUST, H.; VIACAVA, J. J. C.; HUBER, S.; FERNANDES, M. L. Brazilian Validation of Centrality of Religiosity Scale (CRS-10BR and CRS-5BR). Religions, v. 10, p. 508, 2019.

ESPERANDIO, M. R. G.; ESCUDERO, F. T.; FERNANDES, M. L.; PARGAMENT, K. Brazilian Validation of the Brief Scale for Spiritual/Religious Coping-SRCOPE-14. Religions, v. 9, p. 31, 2018

FORNAZARI, S. A.; FERREIRA, R. E. R. Religiosidade/espiritualidade em pacientes oncológicos: qualidade de vida e saúde. Psic.: Teor. e Pesq., Brasília, v. 26, n. 2, p. 265-272, jun. 2010. Disponivel em: $\quad$ http://www.scielo.br/scielo.php?script=sci arttext\&pid=S010237722010000200008\&lng=en\&nrm=iso. Acesso em: 01 out. 2019.

GIORGI, A.; SOUSA, D. Método fenomenológico de investigação em psicologia. Lisboa: Fim de Século, 2010.

KOENIG, H. G.; KING, D. E.; CARSON, V. B. Handbook of religion and health. New York, NY: Oxford University Press, 2012.

KOENIG, H. G. Medicina, religião e saúde: o encontro da ciência e da espiritualidade. Porto Alegre: L\&PM, 2012.

MOREIRA-ALMEIDA, A. Espiritualidade e saúde: passado e futuro de uma relação controversa e desafiadora. Rev. psiquiatr. clín., São Paulo, v. 34, supl. 1, p. 3-4, 2007. Disponível em:

Protestantismo em Revista | São Leopoldo | v. 46, n. 01 | p. 168-182 | Jan./jun. 2020

Disponível em: <http://periodicos.est.edu.br/index.php/nepp> 
http://www.scielo.br/scielo.php?script=sci_arttext\&pid=S0101-

60832007000700001\&lng=en\&nrm=iso. Acesso em: 02 dez. 2017.

PARGAMENT, K. I. Psychology of religion and coping. Theory, Research, Practice. New York: Guilford Press, 1997.

PARGAMENT, K. I.; SMITH, B. W.; KOENIG, H. G.; PEREZ, L. Patterns of Positive and Negative Religious Coping with Major Life Stressors. Journal for the Scientific Study of Religion, 37 (4), 1998. p. $710-724$.

PUCHALSKI, C.; VITILLO, R.; HULL, S. K.; RELLER, N. Improving the spiritual dimension of whole person care: Reaching national and international consensus. J Palliat Med. 2014; 17(6): 642-56. Disponivel em: http://citeseerx.ist.psu.edu/viewdoc/download?doi=10.1.1.866.2561\&rep=rep1\&type=pdf. Acesso em: 28 nov. 2018. 